\title{
ANTIMICROBIAL ACTIVITY AND CHEMICAL COMPOSITION OF TWO EXPERIMENTAL GELS BASED ON ESSENTIAL OILS
}

\author{
LAURA MONICA DASCALU (RUSU) ${ }^{a}$, MARIOARA MOLDOVAN ${ }^{b}$, \\ DOINA PRODAN ${ }^{b}$, IRINA CIOTLAUS ${ }^{b}$, RAHELA CARPA ${ }^{c}$, \\ RAZVAN ENE ${ }^{d, e}$, SORINA SAVA ${ }^{a *}$, RADU CHIFOR $^{f}$, \\ MINDRA EUGENIA BADEA ${ }^{f}$
}

\begin{abstract}
In this study, the comparative testing of the antimicrobial efficacy of 2 experimental photosensitizers (PS-H; PS-T) based on natural compounds with a commercial one based on toluidine blue $O$ (TBO) FotoSan $®$ was performed, by antimicrobial tests with $\mathrm{G}$ - and $\mathrm{G}+$ bacterial strains and through SEM microscopy on dental enamel, using LED phototherapy. For the formulation of the experimental natural photosensitizers we used Frankincense $(T)$ and Thieves $(\mathrm{H})$ essential oils (EO), used as photosensitizing agents in antimicrobial photodynamic therapy in the control of the microbial biofilm of the oral cavity. We also tested the composition of experimental photosensitizers by GC-MS chromatography. Our results suggest that EO should be further investigated as a promising source of natural compounds that can be used to combat bacterial strains. Essential oils can inhibit growth of a broad range of pathogens correlating to their presence in aromatic plants.
\end{abstract}

Keywords: GC-MS, SEM, antibacterial effect

a Department of Prosthodontics and Dental Materials, Iuliu Hatieganu University of Medicine and Pharmacy, 31 Avram lancu str., RO-400083, Cluj-Napoca, Romania

b Department of Polymer Composites, Babes-Bolyai University, Institute of Chemistry Raluca Ripan, 30 Fantanele str., RO-400294, Cluj-Napoca, Romania

c Department of Molecular Biology and Biotechnology, Babeș Bolyai University, Faculty of Biology and Geology, 1 M. Kogălniceanu str.,400084, Cluj-Napoca, Romania

d University of Medicine and Pharmacy Carol Davila Bucharest, 8 Eroii Sanitari str., RO050474 Bucharest, Romania

e Orthopedics and Traumatology Department, Bucharest Emergency University Hospital, 8 Calea Floreasca str., RO- 050098 Bucharest, Romania

f Department of Preventive Dental Medicine, Iuliu Hatieganu University of Medicine and Pharmacy,31 Avram lancu Street, 400083 Cluj-Napoca, Romania

*Corresponding author: savasorina@yahoo.com 


\section{INTRODUCTION}

Since ancient times, essential oils and other plant extracts have proven their potential as sources of natural products. They have been examined for their possible uses as alternative remedies for the treatment of many infectious diseases. The natural alternative to conventional treatment includes the use of medicinal and aromatic plants, which are a major source of natural organic compounds, for the cure of certain diseases [1,2].

Essential oils obtained from medicinal and aromatic plants are complex organic (carbon-containing) chemical entities, which are generally composed of hundreds of chemical compounds, including terpenes, aldehydes, alcohols, esters, phenols, ethers and ketones, which are responsible for the many characteristic properties of the essential oil.

The antimicrobial impact of essential oils and their chemical components have been recognized in the past by several researchers. Literature studies attest the medicinal properties of essential oils, such as anti-inflammatory, healing or antimicrobial activities, but may also be responsible for negative qualities such as photosensitivity and toxicity [3-5].

Understanding the chemistry of essential oils is important for monitoring the composition, which subsequently allows a better understanding of their biological properties. It has been shown that there is a strong correlation between chemical composition and antimicrobial activity.

According to Xiaoqing Hu et al. [6], photosensitizers (PS) are usually unsaturated, double-conjugated organic molecules, which absorb in the visible spectrum, even close to the IR range and which ensure a good penetration of light into tissues. They are chosen according to the way they bind to the surface (membrane) of microbial cells, so that photodynamic therapy can be effective.

The introduction of essential oils in the composition of gels, leads to a slight increase in water retention in conditions of $\mathrm{pH}=4-5$. This behavior suggests the formation of homogeneous materials and can be attributed to the physical interaction through intermolecular hydrogen bonds between the phenolic groups of essential oils and the $-\mathrm{NH}_{2}$ and $-\mathrm{OH}$ groups of the polymer matrix. These intermolecular hydrogen bonds lead to the stabilization of the macromolecule by the formation of a flexible secondary network that allows the diffusion of water molecules through the polymer chains.

The chemical composition of essential oils is relatively complex and about 20 to 60 different bioactive components are observed such as terpenes, terpenoids and other aromatic and aliphatic constituents with low molecular 
weights. Usually, the chemical characterization of many essential oils reveals the presence of only 2-3 major components at a fairly high concentration (20$70 \%)$ compared to other components present in trace amounts. Many of these compounds have antimicrobial activity and the presence of the compounds together can be more powerful than the action of only one compound [7-9].

The novelty of the study consists in the formulation and evaluation of two experimental natural photosensitizers: PS-T with incense essential oil (Frankincense) and PS-H with a mixture of essential oils (Thieves) that combines several essential oils (Clove, Cinnamon Bark, Lemon, Eucalyptus Radiata and Rosemary), used as photosensitizing agents in antimicrobial photodynamic therapy in the control of the microbial biofilm of the oral cavity.

In this study, the comparative testing of the antimicrobial efficacy of 2 experimental photosensitizers (PS-H; PS-T) with a commercial one FotoSan ${ }^{\circledR}$ was performed. In clinical practice FotoSan ${ }^{\circledR}$ (CMS Dental A/S, DK-2800 Kgs. Lyngby) is used for light-activated disinfection in combination with a photosensitizer (FotoSan Agent) containing toluidine blue $O$ (TBO) as an active ingredient, used to catalyse the photochemical process.

\section{RESULTS AND DISCUSSION}

GC-MS analysis shows the volatile compounds specific to experimental PS containing Frankincense essential oil PS-T and Thieves PS-H. The volatile compounds identified from the composition are presented in figure 1 and 2 .

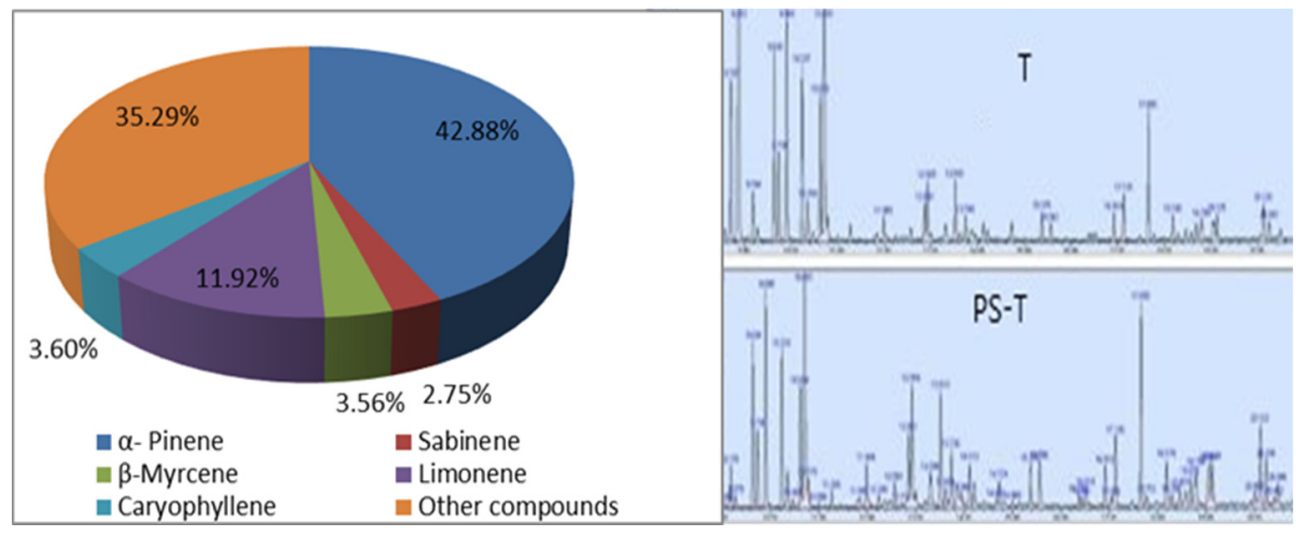

Figure 1. Composition and GC-MS spectra of volatiles identified from photosensitizer (PS-T) and Frankincense (T) essential oil 


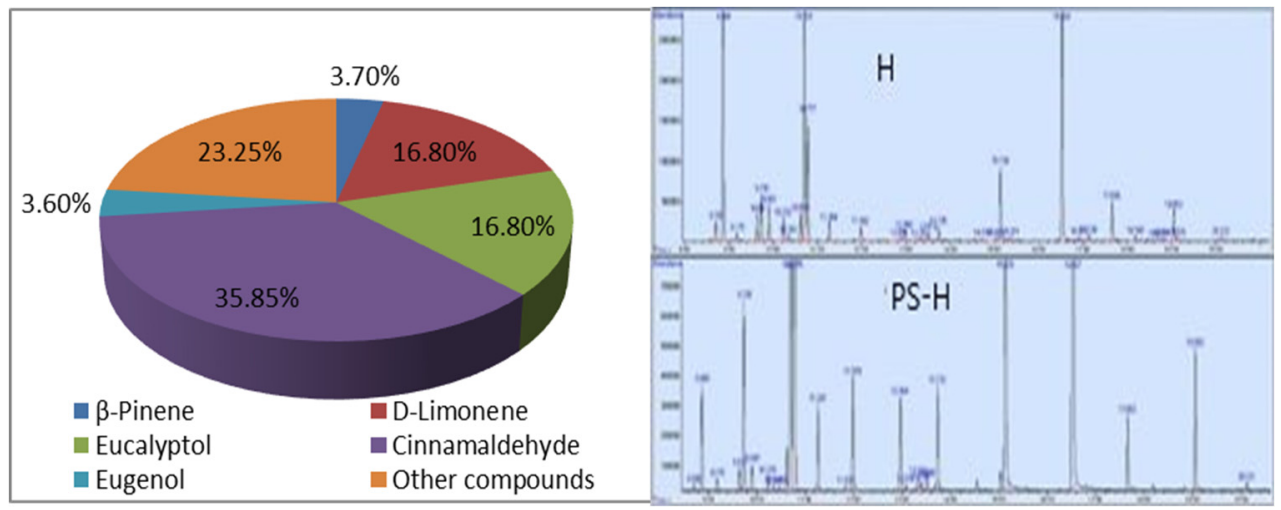

Figure 2. Composition and GC-MS spectra of volatiles identified from photosensitizer (PS-H) and Thieves (H) essential oil

According to several published reports the Frankincense essential oil shows antibacterial and antifungal activity $[10,11]$. This herbal oil with antiinflammatory effect may be applied in the treatment of gingivitis, which is a periodontal tissue inflammatory disease [12,13].

In this study the essential oil was characterized by the high content of monoterpenes, which constituted $84.86 \%$ in which $\alpha$-Pinene and limonene were the major constituents. The remaining $14.53 \%$ was accounted for the sesquiterpenes in which the E-caryophyllene was the major constituent (fig.1).

GC-MS analysis (fig. 2) shows the volatile compounds specific to the mix of essential oils: clove, lemon, cinnamon, eucalyptus, rosemary contained in PS-H gel. Composition of volatiles recovered from PS-H was presented in figure 2. Clove oil (Syzygium aromaticum) is a mixture of different constituents, with three main active ingredients being eugenol, eugenyl acetate and caryophyllene (fig. 2). It is contributed to the antimicrobial and antioxidant properties of the oil $[14,15]$.

The main compounds were limonene, $\gamma$-terpinene, $\beta$-pinene, myrcene, sabinene and citral (fig. 2). Lemon oil is also used for its germicidal, antioxidant and anticarcinogenic properties [16,17].

The major compound of cinnamon EO (essential oil) is cinnamaldehyde, which possesses the strongest antifungal activities [18].

Eucalyptus oil (Eucalyptus radiata), constituent from the oil mix analysed includes: Eucalyptol (1, 8- cineole), beta-pinene, alpha-pinene, alphaphellandrene, para-cymene camphor, isoborneol, levomentol (fig.2). Eucalyptus oil is recognized for its antibacterial and antioxidant properties [19]. The volatile profile of the rosemary essential oil (Rosmarinus officinalis), is given by: alpha pinen, 1.8-cineol (eucalyptol), camphor, camphene, $\beta$-myrcene, limonene. The rosemary essential oil is known to possess insecticidal, antifungal, acaricidal, antibacterial and cytotoxic activities [20,21]. 
The preliminary analysis of the GC chromatograms of the studied EO (essential oils) showed an abundance of several volatile compounds. The main components of Frankincense EO identified in our study were a-Pinene, Limonene and Caryophyllene, while the main constituents of Thieves EO were cinnamaldehyde, eucalyptol and D-limonene.

Major constituents of essential oils with antimicrobial activity include terpenoids such as thymol, carvacrol, para-cymene and cinnamaldehyde. These compounds were demonstrated as components in several of the essential oils tested. $\alpha$ - and $\beta$-pinene are well-known representatives of the monoterpenes group and are found in many essential oils [22]. Pinene $\left(\mathrm{C}_{10} \mathrm{H}_{16}\right)$ is a bicyclic, double bond, terpenoid hydrocarbon. They are among the best-known representatives of a broad family of monoterpenes.

\section{Antimicrobial activity}

Most photosensitizing agents showed antimicrobial activity for both Gram-positive (G+) and Gram-negative (G-) strains.

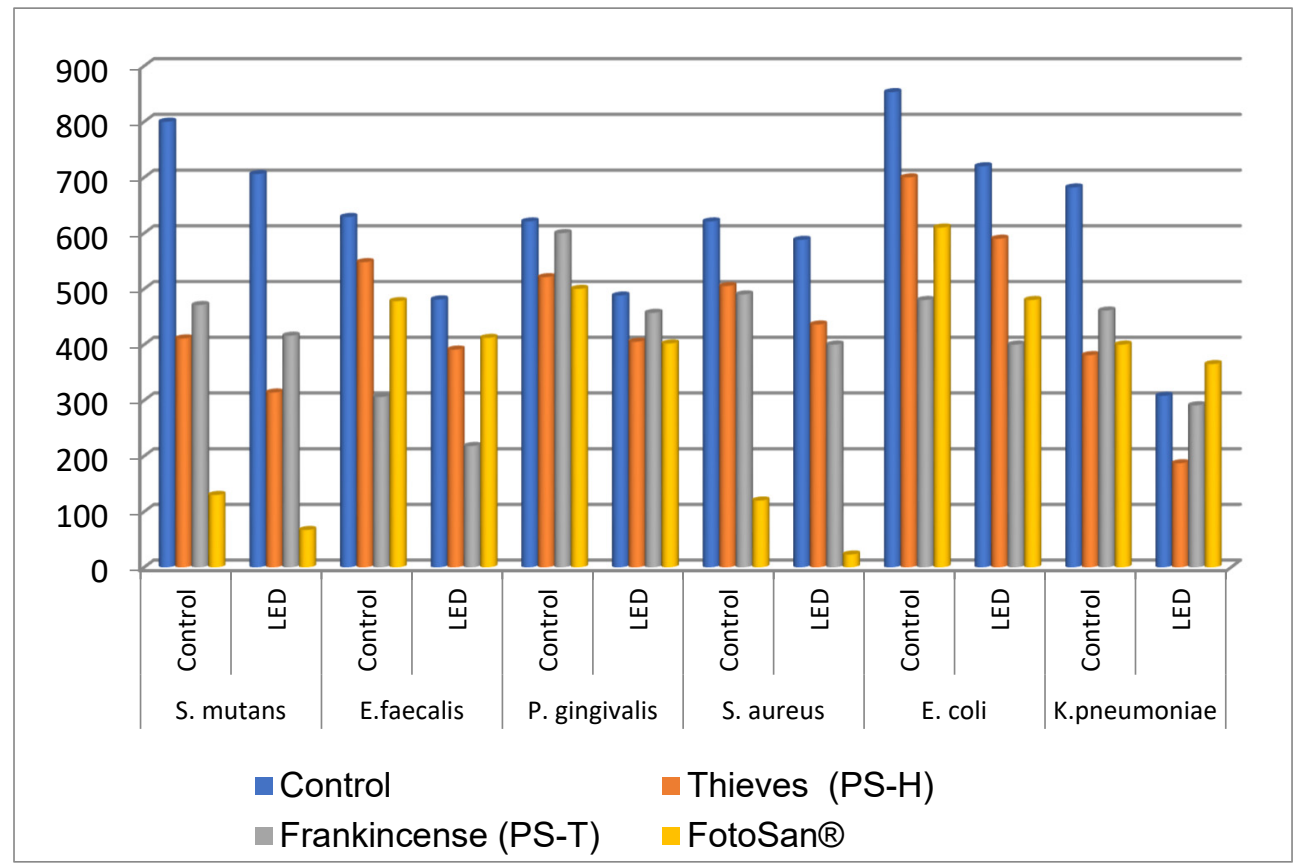

Figure 3. Antimicrobial activity of experimental (PS-T; PS-H) and commercial

(FotoSan) photosensitizers 
In the absence of irradiation, in Control samples, the number of Gram-positive and Gram-negative colonies formed was very high (Fig. 3), in all bacterial strains. In figure 3 can be observed that both experimental photosensitizers showed antibacterial activity compared to the control gel and the effect is comparable to that of the commercial product. The photosensitizer (PS-T) based on incense essential oil (T) had a more pronounced antibacterial effect on $E$. faecalis, S. aureus and E. coli strains. In contrast, the photosensitizer PS-H with a mixture of essential oils $(\mathrm{H})$ showed a more pronounced antibacterial effect on $S$. mutans, $P$. gingivalis and $K$. pneumoniae strains.

Compared to the commercial photosensitizer, the experimental photosensitizers showed a better antimicrobial effect on $E$. faecalis, $P$. gingivalis, E.coli and K. pneumoniae strains. Eucalyptol is a major component of the EO from several species, in particular the Eucalyptus genus and is a recognized antimicrobial agent [23].

According to the antimicrobial results, both samples displayed notable activity towards all tested strains. Frankincense EO exhibited the highest antimicrobial activity on $E$. Faecalis (Gram positive) strain and Thieves EO on K. pneumoniae (Gram negative) strain. The antibacterial effect was increased when the use of the gel based on essential oils was associated with a LED light source. The results of this study are consistent with the data found in the literature. Xiao S. [24] states that Thieves essential oil has an antimicrobial effect on the $S$. aureus strain. The efficacy of photodynamic antimicrobial therapy on extracted teeth, without enamel lesions, was analyzed by SEM, after bacterial colonization and after treatment with PS-T and PS-H.

Representative images of the samples after bacterial colonization and after treatment with experimental and commercial PS are shown in figure 4.

Scanning by electron microscopy (SEM) allows the visualization of three-dimensional surface structures at very different resolutions. In our study, we observed a sensitivity of bacteria to this form of testing, by applying the photosensitizers for 4 minutes and then phototherapy for $1 \mathrm{~min}$.

In figure $4(a, c, e)$ it could be observed initially a well-defined intact bacterial wall, without discontinuities. In figure $4,(b, d, f)$ it could be observed the interrupted bacterial wall both longitudinally and transversely, after a single application of therapy according to the described protocol. Bacterial wall damage is observed following LED phototherapy. 


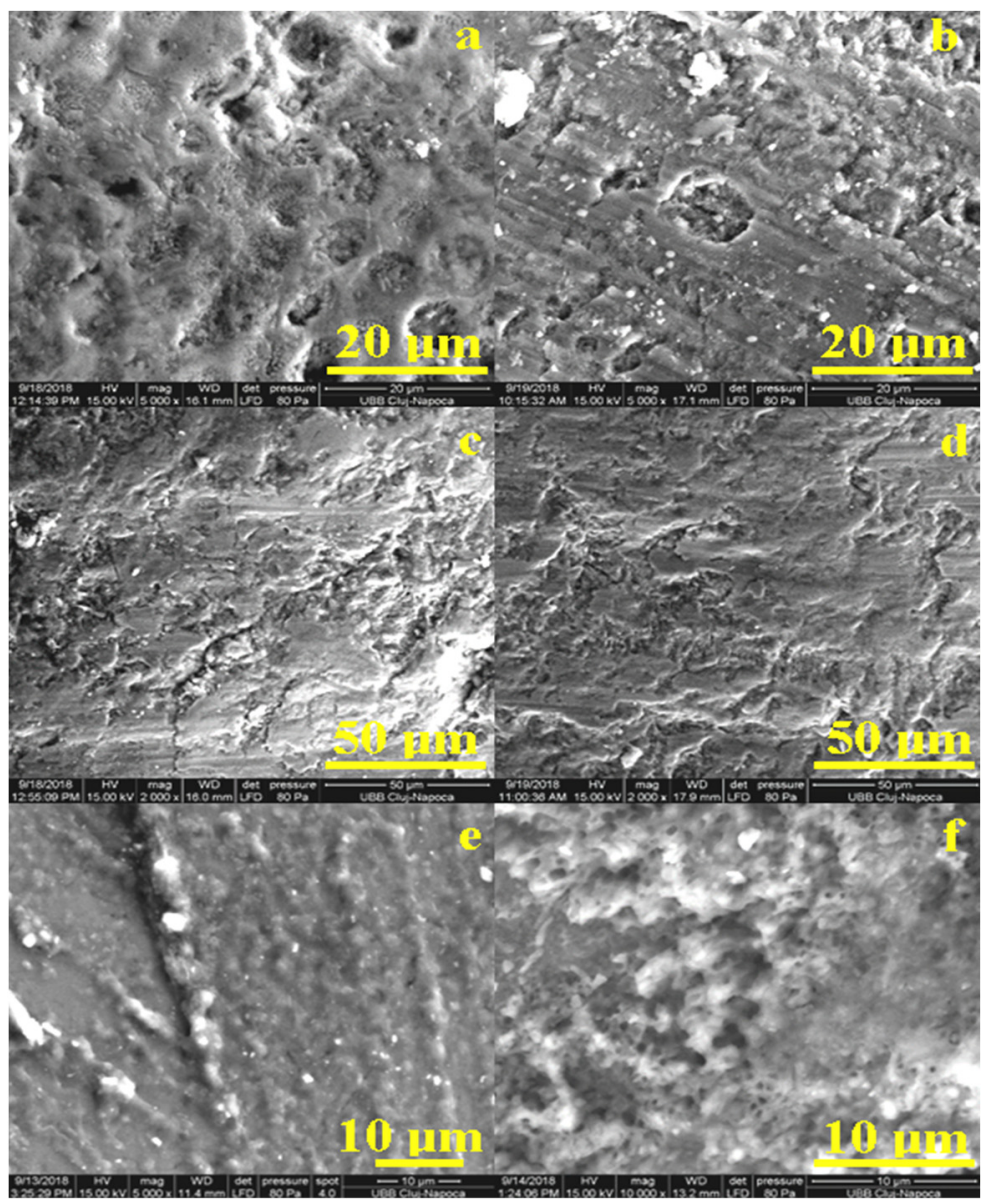

Figure 4. SEM images of enamel teeth at different magnifications: a,c,e) after bacterial colonization and b) after treatment with experimental PS-T and LED;

d) after treatment with experimental PS-H and LED; f) after treatment with commercial FotoSan and LED lamp.

\section{CONCLUSIONS}

Frankincense and Thieves EO as traditional natural medicines, have extensive and significant pharmacological effects and important antimicrobial properties. In this regard, antimicrobial activity of two experimental gels based on essential oils was tested in several strains with a wide range of observed results; the inhibition of 6 bacteria strains has been reported. Single bacteria, as well as monolayer chains or three-dimensional aggregates of bacteria were observed by SEM, confirming the bacterial population in saliva. 
Our results suggest that EO should be further investigated as a promising source of natural compounds that can be used to combat bacteria strains. Essential oils can inhibit growth of a broad range of pathogens correlating to their presence in aromatic plants.

\section{EXPERIMENTAL SECTION}

\section{Obtaining the experimental natural photosensitizers (PS)}

For PS formulation, we used 2 essential oils Frankincense $(T)$ and Thieves $(\mathrm{H})$ from Young Living, 9727 AJ Groningen, Netherlands. Thieves contains a mixture of Clove, Cinnamon Bark, Lemon, Eucalyptus Radiata and Rosemary essential oils.

Gels based on natural compounds used as photosensitizers in photodynamic therapy (PDT) were used in the experimental study.

The experimentally PS were prepared from a mixture of gelatin: glycerol (Sigma-Aldrich Inc., St. Louis, USA) in a weight ratio of $1: 1$ and $60 \mathrm{ml}$ Kaqun ${ }^{\circledR}$ water (Harghita, 535600, Romania), using the following procedure: gelatine and glycerol with $0.015 \%$ salicylic acid solution were added to the water.

Experimental photosensitizers were characterized by chromatographic analysis (GC-MS) and the antibacterial effect was evaluated on six grampositive and gram-negative bacterial strains. The effect of antimicrobial photodynamic therapy on tooth enamel was evaluated by SEM microscopy.

\section{The gas chromatography - mass spectrometry (GC-MS)}

For this study were used two type of gels, gel with Frankincense essential oil $(T)$ and Thieves $(H)$, a mixture of essential oils, as antibacterial agents with applications in dentistry. By the GC-MS analysis technique we identified the chemical composition of the tested essential oils.

GS-MS, sample processing: $(0.5 \mathrm{~g})$ were dispersed in hexan $(10 \mathrm{~mL})$ for $2 \mathrm{~h}$, then was ultrasonicated for 15 minutes and centrifuged at $4400 \mathrm{rpm}$ for 15 minutes. The volatile fraction in hexan was filtered and then dried over sodium sulfate. The essential oil recovered from gel was injected into GC-MS.

GC-MS Method: Agilent GC-MS Gas Chromatograph - 7890A/5975/ 2008 (Agilent Technologies, Inc. Europe, Waldbronn, Germany) was used for analysis; GC-MS analyzes were performed in scan mode on a DB-5MS $(30 \mathrm{~m} \times 0.25 \mathrm{~mm} \times 0.25 \mu \mathrm{m})$ capillary column (Agilent 19091S-433M), high 
purity He carrier gas at a flow rate of $1 \mathrm{~mL} / \mathrm{min}$. Temperature program: initial temperature $40^{\circ} \mathrm{C}$ with a ramp of $8^{\circ} \mathrm{C} / \mathrm{min}$ up to $220^{\circ} \mathrm{C}$, then with $20^{\circ} \mathrm{C}$ up to $280^{\circ} \mathrm{C}$ and maintained $5 \mathrm{~min}$, injector temperature $250^{\circ} \mathrm{C}$, injection volume of $1 \mu \mathrm{L}, 100$ : 1 slides, MS $70 \mathrm{eV}$, mass range u.a.m. 30-400. NIST library was used for identification/ confirmation of the structure components. In addition, a C8-C20 standards alkanes (Alkane Standard Solution C8-C20, Sigma Aldrich) was used for calculation of the linear retention index (RI), and matching the experimental values with those reported in the literature for similar chromatographic columns, in the same condition.

\section{Antimicrobial activity}

\section{Microbial strains}

The essential oils were tested against 6 Gram positive and Gram negative bacteria. The Gram positive bacteria strains were: Staphylococcus aureus ATCC 6538, Streptococcus mutans ATCC 25175, Enterococcus faecalis ATCC 29212. The Gram negative bacteria strains were: Escherichia coli ATCC 25922, Klebsiella pneumoniae ATCC 4352, Porphyromonas gingivalis ATCC 33277.

\section{Determination of bactericidal activity}

For each bacterial strain, 96-well plates were used. For each plate 3 types of photosensitizing agents were inoculated in triplicate and for each bacterial strain to be tested. From fresh colonies of bacteria grown on Mueller-Hinton medium, bacterial suspensions were made in $\mathrm{BHI}$ broth adjusted to a turbidity of $0.5 \mathrm{McF}$ arland. $150 \mu \mathrm{L}$ of bacterial suspension and $125 \mu \mathrm{L}$ of photosensitizing agents were placed in each well. The inoculated plates were placed in the dark 5 minutes before irradiation. One board was kept for CONTROL and one was subjected to LED lighting with Fotosan lamp (630nm, $40 \mathrm{~mW} / \mathrm{cm}^{2}$ ).

\section{SEM analysis}

The irradiation time for each well was $60 \mathrm{sec}$. After irradiation, the 96well plates were placed in an incubator at $37^{\circ} \mathrm{C}$ for $24 \mathrm{~h}$. To assess bacterial viability, $50 \mu \mathrm{L}$ of each sample was mixed with $200 \mu \mathrm{L}$ sterile PBS and placed on Petri dishes with Mueller-Hinton solid culture medium. These plates were again incubated at $37^{\circ} \mathrm{C}$ for $24 \mathrm{~h}$. After incubation, the colonies appeared for each sample of the 3 experimental variants and were counted. 
In order to evaluate the efficiency of photodynamic therapy and the formulated experimental PS, we used enamel teeth with no lesions $(n=30)$. The extracted teeth were immersed in natural saliva, collected from subjects with high carioreceptivity. They were then incubated at $37^{\circ} \mathrm{C}$ for at least 48 hours. After the initial examination, photosensitizers (PS-T; PS-H, FotoSan) were applied on the teeth for 4 minutes. After this time, PS was removed by rinsing with $0.9 \%$ saline, taking care that the jet did not act directly on the area of interest to avoid mechanical removal of bacteria.

Dental surfaces were subjected to photodynamic therapy using the LED phototherapy with Fotosan lamp (630 nm, $\left.40 \mathrm{~mW} / \mathrm{cm}^{2}\right)$. for 1 minute. To evaluate the antibacterial effect, dental surface was examined by SEM (Inspect S, FEICompany) before and after the application of photosensitizers and LED irradiation.

The researches were on extracted teeth and all subjects gave their informed consent for inclusion before they participated in the study. The study was conducted in accordance with the Declaration of Helsinki and the protocol was approved by the Research Ethics Committee of the University of Medicine and Pharmacy "luliu Hatieganu", Cluj-Napoca, Romania (authorization no. 578/10.12.2019).

\section{REFERENCES}

1. G.N. Teke; K. . Elisée; K.J. Roger; BMC Complement. Altern. Med.,2013,13, 130.

2. M.K. Swamy; U.R. Sinniah; Molecules, 2015, 20, 8521-8547.

3. M.K. Swamy; M.S. Akhtar; U.R. Sinniah; Evid. Based. Complement. Alternat. Med., 2016, 2016, 3012462, 21 p.

4. A. Orchard; S. van Vuuren; Evid. Based. Complement. Alternat. Med., 2017, 2017, 4517971, $92 \mathrm{p}$

5. M. Valdivieso-Ugarte; C. Gomez-Llorente; J. Plaza-Díaz; Á. Gil; Nutrients., 2019, 11, 2786.

6. X. Hu; Y.Y. Huang; Y. Wang; X. Wang; M.R. Hamblin; Front Microbiol., 2018, 9, 1299.

7. J.E. Patterson; L. McElmeel; N.P. Wiederhold; Open Forum Infect. Dis., 2019, 6 , ofz502.

8. N.A. Mahizan; S.K. Yang, C.L. Moo, A.A.L. Song; C.M. Chong; C.W. Chong; A. Abushelaibi; S.H.E. Lim; K.S. Lai; Molecules.,2019, 24, 2631.

9. B. Salehi; S. Upadhyay; I. Erdogan Orhan; A.K. Jugran; S.L.D. Jayaweera; D.A. Dias; F. Sharopov; Y. Taheri; N. Martins; N. Baghalpour; W.C. Cho; J. SharifiRad; Biomolecules, 2019, 9, 738. 
10. T. Umezu; Jpn. J. Pharmacol., 2000, 83, 150-153.

11. A. Ali; M. Wurster; N. Arnold; A. Teichert; J. Schmidt; U. Lindequist; L. Wessjohann; Rec. Nat. Prod., 2008, 2, 6-12.

12. M.K. Samani; H. Mahmoodian; A. Moghadamnia; A.P.B. Mir; M. Chitsazan; DARU J. Pharmaceutical Sci., 2011, 19, 288-294.

13. T. Lakshmi; R. Rajesvari; A. Selvaraj; R. Parameswari; J. Adv. Pharmacy Education \& Res., 2017, 7, 182-186.

14. B. Amelia; E. Saepudin; A.H. Cahyana; D. U. Rahayu; A. S. Sulistyoningrum; J. Haib; AIP Conference Proceedings, 2017, 1862, 030082.

15. L. Jirovetz; G. Buchbauer; I. Stoilova; A. Stoyanova; A.E. Krastanov; J. Schmidt; J. Agric. Food Chem., 2006, 54, 6303-6307.

16. A. Gök; Ş. Ismail Kirbaşlar; F. Gülay Kirbaşlar; J.Essent. Oil Res., 2015, 27, 17-22.

17. F. Spadaro; C. Circosta; R. Costa; F. Pizzimenti; D.R. Palumbo; F. Occhiuto; J. Essent. Oil Res., 2012, 24, 187-193.

18. K. Małgorzata Brodowska; A.J. Brodowska; K. Śmigielski; Eur. J. Biol. Res., 2016, 6, 310-316.

19. R.K. Bachheti; Der Pharma Chemica, 2015, 7, 209-214.

20. S.A. Socaci; M. Tofană; C. Socaciu; Bulletin UASVM, Agriculture, 2008, 65, 405-409.

21. V. Miclea; I. Donca; M. Culea; N. Fiţ; P. Podea; Studia UBB Chemia, 2019, 2, 127-138.

22. M. Soškić; D. Bojović, V. Tadić; Studia UBB Chemia, 2016, 2, 127-136.

23. A. Nafis; A. Kasrati; C.A. Jamali; L. Custódio; S. Vitalini; M. Iriti; L. Hassani; Antibiotics, 2020, 9, 140.

24. S. Xiao; P. Cui; W. Shi, Y. Zhang; BMC Complement Med. Ther., 2020, 20, 99.3. 